\title{
Transition metal oxides on organic semiconductors
}

\author{
Yongbiao Zhao ${ }^{a}$, Jun Zhang ${ }^{b}$, Shuwei Liu ${ }^{a}$, Yuan Gao ${ }^{\mathrm{a}, \mathrm{b}}$, Xuyong Yang ${ }^{\mathrm{a}}$, Kheng Swee Leck ${ }^{\mathrm{a}}$, \\ Agus Putu Abiyasa ${ }^{\mathrm{a}}$, Yoga Divayana ${ }^{\mathrm{a}}$, Evren Mutlugun ${ }^{\mathrm{a}}$, Swee Tiam Tan ${ }^{\mathrm{a}}$, Qihua Xiong ${ }^{\mathrm{b}}$, \\ Hilmi Volkan Demir ${ }^{\mathrm{a}, \mathrm{b}, \mathrm{c}, *}$, Xiao Wei Sun ${ }^{\mathrm{a}, \mathrm{d}, *}$ \\ ${ }^{a}$ Luminous! Center of Excellence for Semiconductor Lighting and Displays, School of Electrical and Electronic Engineering, Nanyang Technological University, 50 \\ Nanyang Avenue, Singapore 639798, Singapore \\ ${ }^{\mathrm{b}}$ Division of Physics and Applied Physics, School of Physical and Mathematical Sciences, Nanyang Technological University, 21 Nanyang Link, Singapore 637371, \\ Singapore \\ ${ }^{\mathrm{c}}$ Department of Physics, Department of Electrical and Electronics Engineering, and UNAM-Institute of Materials Science and Nanotechnology, Bilkent University, \\ TR-06800 Ankara, Turkey \\ d South University of Science and Technology, Shenzhen, Guangdong 518055, China
}

\section{A R T I C L E I N F O}

\section{Article history:}

Received 21 November 2013

Received in revised form 7 January 2014

Accepted 14 January 2014

Available online 1 February 2014

\section{Keywords:}

p-doping

Transition metal oxide

Organic semiconductor

Diffusion

Organic light-emitting diode

\begin{abstract}
A B S T R A C T
Transition metal oxides (TMOs) on organic semiconductors (OSs) structure has been widely used in inverted organic optoelectronic devices, including inverted organic light-emitting diodes (OLEDs) and inverted organic solar cells (OSCs), which can improve the stability of such devices as a result of improved protection of air sensitive cathode. However, most of these reports are focused on the anode modification effect of TMO and the nature of TMO-on-OS is not fully understood. Here we show that the OS on TMO forms a two-layer structure, where the interface mixing is minimized, while for TMO-on-OS, due to the obvious diffusion of TMO into the OS, a doping-layer structure is formed. This is evidenced by a series of optical and electrical studies. By studying the TMO diffusion depth in different OS, we found that this process is governed by the thermal property of the OS. The TMO tends to diffuse deeper into the OS with a lower evaporation temperature. It is shown that the TMO can diffuse more than $20 \mathrm{~nm}$ into the OS, depending on the thermal property of the OS. We also show that the TMO-on-OS structure can replace the commonly used OS with TMO doping structure, which is a big step toward in simplifying the fabrication process of the organic optoelectronic devices.
\end{abstract}

(c) 2014 Elsevier B.V. All rights reserved.

\section{Introduction}

Recently, transition metal oxides (TMOs) [1,2], such molybdenum trioxide $\left(\mathrm{MoO}_{3}\right)$ [3], tungsten oxide $\left(\mathrm{WO}_{3}\right)$ [4], vanadium pentoxide $\left(\mathrm{V}_{2} \mathrm{O}_{5}\right)$ [5] and rhenium trioxide $\left(\mathrm{ReO}_{3}\right)[6]$, have gained great attention because of their

\footnotetext{
* Corresponding authors at: Luminous! Center of Excellence for Semiconductor Lighting and Displays, School of Electrical and Electronic Engineering, Nanyang Technological University, 50 Nanyang Avenue, Singapore 639798, Singapore.

E-mail addresses: volkan@stanfordalumni.org (H.V. Demir),
} exwsun@ntu.edu.sg (X.W. Sun). wide applications in optoelectronic devices composed of organic semiconductors (OSs). For example, in organic light-emitting diodes (OLEDs) [7], they are used as anode modification interlayers [3], which can substantially reduce the hole injection barrier. They are also key components of charge generation layer in tandem OLEDs [8-10]. In organic solar cells (OSCs) [11], they are employed as charge extraction interlayer [12-14] and recombination layer $[15,16]$. These TMOs have many unique properties, such as high work function, semiconducting and good transparency, that are all very important for electrode interlayers and/or as charge generation/recombination materials. Among these properties, the high work function 
is the main reason for efficient operation of these TMO based functional layers. For example, thermal evaporated $\mathrm{MoO}_{3}$ and $\mathrm{WO}_{3}$ thin film have a high work function of $6.9 \mathrm{eV}$ [17] and $6.7 \mathrm{eV}$ [18], respectively, which are lying much lower than the highest occupied molecular orbital (HOMO) levels of most OSs and result in electron transfer from HOMO of OSs to conduction band (CB) of the TMOs (which is also termed as converting a hole current into an electron current) [1]. This process makes them popular choice to modify most electrodes (e.g., ITO [3], Au [19], Ag [20], Al [13], PEDOT:PSS [21,22] and graphene [23]) for efficient anodes in OLEDs and OSCs. This also makes them efficient p-type dopant. For example, with doping levels varying from intrinsic to high concentrations of up to $25 \mathrm{~mol} . \%$ of $\mathrm{MoO}_{3}$, the current density in $4,4^{\prime}-\mathrm{N}, \mathrm{N}^{\prime}$-dicarbazole-biphenyl (CBP) based hole only device can be manipulated within a range of five orders of magnitude [24], which provides a direct evidence of p-doping by $\mathrm{MoO}_{3}$.

Recently, inverted optoelectronic devices including inverted OLEDs [25], inverted quantum dot-LEDs [26] and inverted OSCs $[13,27]$ have been extensively studied, owning to their ability to further improve the device stability compared with conventional structures. In these devices, TMOs have been widely employed due to their capability we mentioned above that they can modify almost all electrodes for efficient hole injection/extraction. The electrode modification effect in inverted devices is the same as that in normal devices. The difference between inverted and normal device structure is that, in the normal device structure, the hole transporting/extraction layer is deposited on TMO and in the inverted device structure, however, the TMO is deposited on the hole transporting/extraction layer instead. Interestingly, it is generally assumed that there is no difference between the OS-on-TMO and TMO-on-OS structures. However, we shall show it is not the case, at least in the system we studied.

Besides this, several studies $[22,28,29]$ show that by introducing thin TMO film in the intermediate of OSs helps to improve the hole current and the cause was credited to the improved hole transport as a result of charge transfer (CT) complex formation at the interface between TMO and OS. For example, compared with ITO/NPB(40 nm)/Al structure, ITO/NPB(10 nm)/ $\mathrm{MoO}_{3}(3 \mathrm{~nm}) /$ $\mathrm{NPB}(30 \mathrm{~nm}) / \mathrm{Al}$ shows improved hole current [29]. The explanation of CT complex is based on the hypothesis that the OS and TMO thin films form a two-layer structure, where inter-diffusion between the OS and TMO is ignored. However, this inter-diffusion process between OS and TMO thin films sometimes can be underestimated, especially when depositing TMO on OS. Previous study indicates that, after depositing metal Li on OS, the diffusion depth of $\mathrm{Li}$ into OS can be up to $70 \mathrm{~nm}$ depending on the choice of the OS [30]. If similar process exists in TMO-on-OS structure, the mechanism for the improvement of the hole current should be revised. For example, in the case of $\mathrm{ITO} / \mathrm{NPB}(10 \mathrm{~nm}) / \mathrm{MoO}_{3}(3 \mathrm{~nm}) / \mathrm{NPB}(30 \mathrm{~nm}) /$ $\mathrm{Al}$, if the diffusion depth of $\mathrm{MoO}_{3}$ into NPB is larger than $10 \mathrm{~nm}$, the interface between ITO and NPB can be efficiently modified, which can also improve the hole current in the device.

In this paper, we have investigated the possibility of TMOs diffusion into OSs in the TMO-on-OS structure. It is shown that the diffusion process indeed exists. With $\mathrm{MoO}_{3}$-on-NPB as a typical example, we show that the absorption of thin film of $\mathrm{MoO}_{3}$-on-NPB is quite different from that of NPB-on- $\mathrm{MoO}_{3}$. However, it is much similar to $\mathrm{MoO}_{3}$ doped NPB thin film, indicating in the $\mathrm{MoO}_{3}$-on-NPB structure $\mathrm{MoO}_{3}$ is sufficiently mixed with NPB. By studying the current density-voltage $(J-V)$ properties of a series devices with structure of $\operatorname{ITO} / \mathrm{NPB}(x \mathrm{~nm}) / \mathrm{MoO}_{3}(3 \mathrm{~nm}) /$ $\mathrm{NPB}(165-x \mathrm{~nm}) / \mathrm{MoO}_{3} / \mathrm{Al}$, we show that $\mathrm{MoO}_{3}$ can diffuse into NPB up to $15 \mathrm{~nm}$. We also studied $\mathrm{MoO}_{3}$ with other OSs including 4,4', 4" -Tri(9-carbazoyl)triphenylamine (TCTA) and $\mathrm{CBP}$, and the resulting diffusion depth of $\mathrm{MoO}_{3}$ into TCTA and CBP is found to be up to $10 \mathrm{~nm}$ and $20 \mathrm{~nm}$, respectively. By considering the thermal properties of NPB, TCTA and CBP, it is clear that the more thermal stable the OS is, the shorter depth the $\mathrm{MoO}_{3}$ can diffuse into the OS. We also show that the diffusion of TMO into OS is good for simplifying the fabrication process of an organic electronic device. With OLEDs as an example, we employ $\mathrm{MoO}_{3}$-on-CBP as hole transporting layer (HTL), the result device performance is found comparable to the device based on $\mathrm{MoO}_{3}$ doped CBP HTL. This suggest that TMO-on-OS structure can replace the TMO doped OS structure, which eliminates the complex concentration control of the co-doping process in TMO doped OS structure. Hence, besides understanding the device physics, our finding could contribute to a more simplified organic device fabrication process.

\section{Experimental}

All devices were fabricated on commercial ITO-coated glass substrates. The ITO substrates were treated in order by ultrasonic bath sonication of detergent, de-ionized water, isopropanol and acetone, each with a 20 min interval. Then the ITO substrates were dried with nitrogen gas and baked in an oven at $80^{\circ} \mathrm{C}$ for $30 \mathrm{~min}$. Subsequently, the substrates were transferred into a thermal evaporator, where the organic, inorganic and metal functional layers were deposited sequentially at a base pressure lower than $4 \times 10^{-4} \mathrm{~Pa}$. The evaporation rates were monitored with several quartz crystal microbalances located above the crucibles and thermal boats. For organic semiconductors and metal oxides, the typical evaporation rates were about $0.1 \mathrm{~nm} / \mathrm{s}$ and for aluminum, the evaporation rate was $1-5 \mathrm{~nm} / \mathrm{s}$. For the co-doping process, the rates of each material can be precisely monitored by the quartz crystal microbalances. The intersection of Al and ITO forms a $3 \mathrm{~mm} \times 3 \mathrm{~mm}$ active device area. For the absorption measurement, the samples were prepared on quartz substrate, which also underwent the same washing steps as the ITO substrates. The absorption spectrum was carried out on a LAMBDA 950 UV/Vis/NIR Spectrophotometer. $J-V$ and $L-V$ data were collected with a source meter (Yokogawa GS610) and a luminance meter (Konica Minolta LS-110) with a customized Labview program. The lifetime study was performed in nitrogen filled glovebox. 


\section{Results and discussions}

3.1. Identification of the diffusion process of TMO into OS by absorption spectrum study

In this study, we employed $\mathrm{MoO}_{3}$ as the typical TMO and NPB as the typical OS to study the possibility of TMO diffusion into OS. To identify whether $\mathrm{MoO}_{3}$ can diffuse into NPB, it is much easier to see if there is any difference in the absorption spectra of the thin film of NPB-on- $\mathrm{MoO}_{3}$ and $\mathrm{MoO}_{3}$-on-NPB. If the diffusion process is obvious, the underlying NPB film can be sufficiently p-doped by $\mathrm{MoO}_{3}$, which would result in additional absorption in the near infrared (NIR) region [6,31,32]. To check this hypothesis, we have prepared four samples with structures of quartz/NPB(10 nm), $\quad$ quartz/$/ \mathrm{MoO}_{3}(3 \mathrm{~nm}) / \mathrm{NPB}(10 \mathrm{~nm})$, quartz/NPB $(10 \mathrm{~nm}) / \mathrm{MoO}_{3}(3 \mathrm{~nm})$ and quartz/23.1 vol.\% $\mathrm{MoO}_{3}$ doped $\mathrm{NPB}(13 \mathrm{~nm})$. The absorption spectra of the four samples are shown in Fig. 1. As shown, the absorption of $10 \mathrm{~nm} \mathrm{NPB}$ on $3 \mathrm{~nm} \mathrm{MoO}$ mimics that of pure NPB film, indicating the interaction of the underlying $\mathrm{MoO}_{3}$ with the upper NPB layer is very small. However, for $3 \mathrm{~nm} \mathrm{MoO}_{3}$ on $10 \mathrm{~nm} \mathrm{NPB}$, the condition is quite different. Compared with pure NPB film, two additional absorption peaks emerge, one locating around $400-500 \mathrm{~nm}$ and the other spanning from 900 to $1880 \mathrm{~nm}$. These two features are almost the same as that of $\mathrm{MoO}_{3}$ doped NPB film. This indicates that in the $\mathrm{MoO}_{3}$-on-NPB structure, the inter-mixing of $\mathrm{MoO}_{3}$ and NPB is quite sufficient and NPB is strongly p-doped by $\mathrm{MoO}_{3}$.

\subsection{Determination of the extent of diffusion by $J-V$ study}

As we have identified the fact of $\mathrm{MoO}_{3}$ can diffuse into NPB in $\mathrm{MoO}_{3}$-on-NPB structure, it would be meaningful to understand the effect of the diffusion process on the charge carrier dynamics in the device based on TMO-on-OS structure. To do this, we investigate the $J-V$ characteristics of a series hole only devices (HODs) with a common structure of ITO/NPB $(x \mathrm{~nm}) / \mathrm{MoO}_{3}(3 \mathrm{~nm}) / \mathrm{NPB}(165-x \mathrm{~nm}) / \mathrm{MoO}_{3}$ $(3 \mathrm{~nm}) / \mathrm{Al}$, with the first NPB interlayer thickness $x(\mathrm{~nm})$

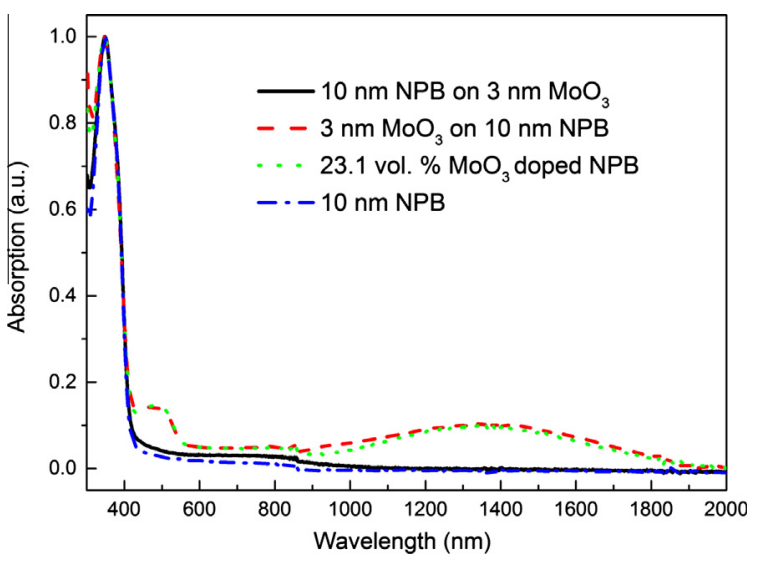

Fig. 1. Absorption spectra of NPB, NPB-on- $\mathrm{MoO}_{3}, \mathrm{MoO}_{3}-\mathrm{on}-\mathrm{NPB}$ and $\mathrm{MoO}_{3}$ doped NPB thin films. varies from 0 to 40 . The $\mathrm{MoO}_{3}$ layer between NPB and $\mathrm{Al}$ was used to block the electrons [24]. As shown in Fig. 2a, with $x$ increasing from 0 to $15 \mathrm{~nm}$, the current density grows gradually. With $x=20 \mathrm{~nm}$, the current density exhibits a little decrease with respect to the case of
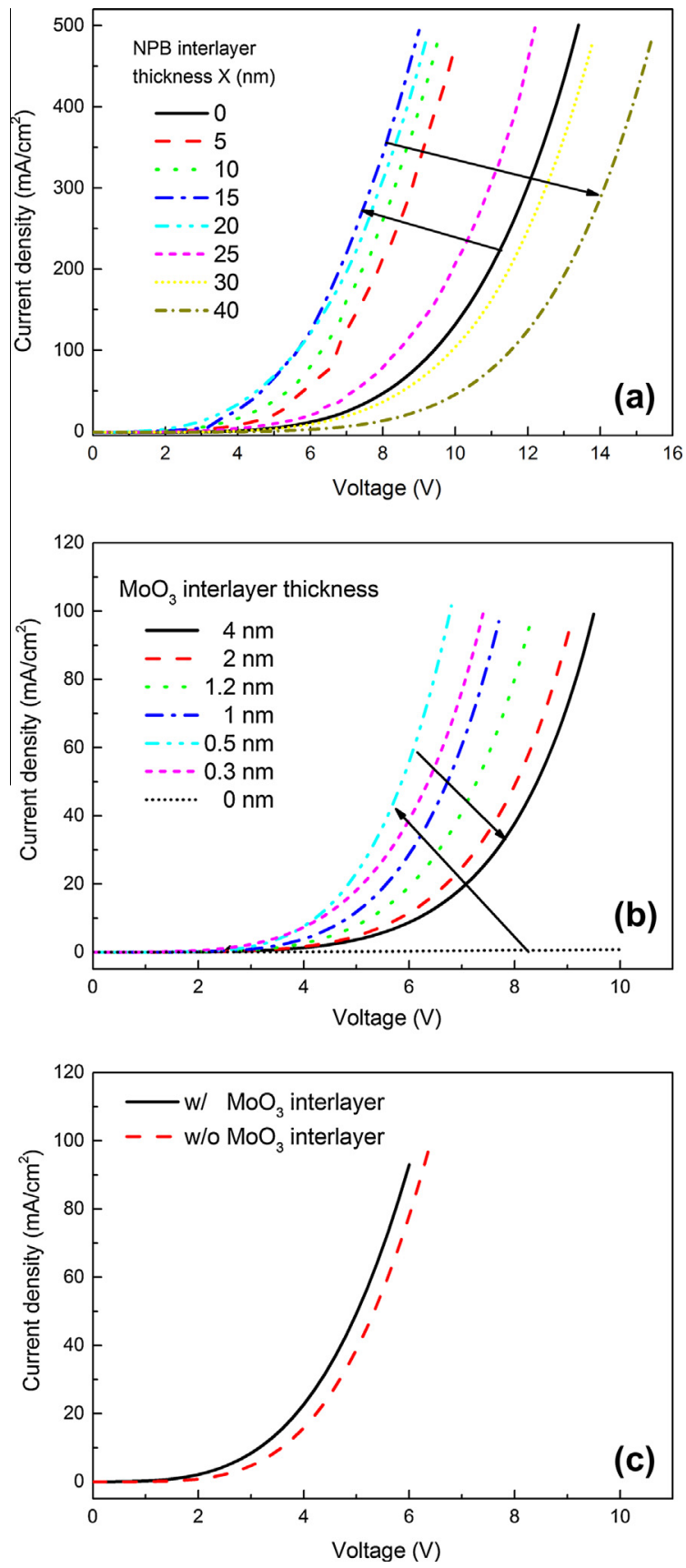

Fig. 2. (a) $J-V$ curves of the hole only devices using a structure of ITO/ $\mathrm{NPB}(x \mathrm{~nm}) / \mathrm{MoO}_{3}(3 \mathrm{~nm}) / \mathrm{NPB}(165-x \mathrm{~nm}) / \mathrm{MoO}_{3}(3 \mathrm{~nm}) / \mathrm{Al}$, with $x$ varied from 0 to $40 \mathrm{~nm}$, (b) $J-V$ curves of the hole only devices using a structure of ITO/MoO $(x \mathrm{~nm}) / \mathrm{NPB}(165 \mathrm{~nm}) / \mathrm{MoO}_{3}(3 \mathrm{~nm}) / \mathrm{Al}$, with $x$ varied from 0 to $4 \mathrm{~nm}$, and (c) $J-V$ curves of the hole only devices using a structure of ITO/ $\mathrm{MoO}_{3}(0.5 \mathrm{~nm}) / \mathrm{NPB}(50 \mathrm{~nm}) / \mathrm{MoO}_{3}(0$ or $3 \mathrm{~nm}) / \mathrm{NPB}(115 \mathrm{~nm}) / \mathrm{MoO}_{3}(3 \mathrm{~nm}) /$ Al. 
$x=15 \mathrm{~nm}$. However, further increase in the NPB interlayer thickness results in a substantial decrease in the current density.

Here, the $J-V$ characteristic is governed by two main factors: one is the hole injection from ITO anode to the first NPB interlayer and the other is the hole transportation in NPB. The $\mathrm{MoO}_{3}$ diffusion into NPB can affect the hole injection and transportation at the same time. However, the extents of these two effects are different. Compared with the thickness of the whole NPB layer, the thickness of doped NPB interlayer is quite small, and even assuming the doped NPB interlayer has no resistance, the hole current improvement due to the improved hole transportation in the $\mathrm{p}$ doped NPB interlayer should be less than $10 \%$ for an NPB interlayer thickness of $15 \mathrm{~nm}$, for example. However, for the hole injection, the effect could be quite large. To differentiate these two effects, we carried out a separate experiment. First, we identified the optimum thickness of $\mathrm{MoO}_{3}$ on ITO for best hole injection into NPB. Matsushima et al. have studied the hole injection from $\mathrm{MoO}_{3}$ modified ITO into $\mathrm{N}, \mathrm{N}^{\prime}$-bis(naphthalen-1-yl)-N,N'-bis(phenyl)-2,2'-dimethylbenzidine( $\alpha$-NPD) and reported that the optimum thickness $x$ of $\mathrm{MoO}_{3}$ on ITO in a HOD using a structure of $\mathrm{ITO} / \mathrm{MoO}_{3}(x \mathrm{~nm}) / \alpha-\mathrm{NPD}(100 \mathrm{~nm}) / \mathrm{MoO}_{3}(10 \mathrm{~nm}) / \mathrm{Al}$ was as low as $0.75 \mathrm{~nm}$ and, from their data, it can be estimated that the hole only device with $10 \mathrm{~nm} \mathrm{MoO}_{3}$ has one magnitude lower current density than the one with $0.75 \mathrm{~nm} \mathrm{MoO}_{3}$ at the same voltage [32]. In our study, we use a device structure of ITO $/ \mathrm{MoO}_{3}(x \mathrm{~nm}) / \mathrm{NPB}(165 \mathrm{~nm}) / \mathrm{MoO}_{3}(3 \mathrm{~nm}) / \mathrm{Al}$, where $x$ varies from 0 to $4 \mathrm{~nm}$. As shown in Fig. 2b, our experiment shows similar behaviour. With $x=0 \mathrm{~nm}$, the holes can be hardly injected into the device due to a very large hole injection barrier between the untreated ITO and NPB and with $0.3 \mathrm{~nm} \mathrm{MoO}$ the hole injection is greatly improved. The optimum $\mathrm{MoO}_{3}$ thickness was determined to be about $0.5 \mathrm{~nm}$, which is comparable to the report by Matsushima. Further increase in $\mathrm{MoO}_{3}$ thickness results in decreased hole injection. Comparing the devices with $0.5 \mathrm{~nm}$ and $4 \mathrm{~nm}$ $\mathrm{MoO}_{3}$, a 5 -fold decrease in the hole current density is observed. From these data, it is clear that, the hole injection interface alone can affect the hole current significantly.

In the next step, we need to identify the extent of the p-doping effect. The used device structures are ITO/ $\mathrm{MoO}_{3}(0.5 \mathrm{~nm}) / \mathrm{NPB}(50 \mathrm{~nm}) / \mathrm{MoO}_{3}(0 \mathrm{~nm}$ or $3 \mathrm{~nm}) / \mathrm{NPB}$ $(115 \mathrm{~nm}) / \mathrm{MoO}_{3}(3 \mathrm{~nm}) / \mathrm{Al}$. As can be seen, the difference between the two devices is that, the one with $3 \mathrm{~nm}$ $\mathrm{MoO}_{3}$ on the first $50 \mathrm{~nm}$ NPB layer will have the first $50 \mathrm{~nm}$ NPB layer partially p-doped. The $J-V$ curves of the two devices are shown in Fig. 2c. As shown, the one with $3 \mathrm{~nm} \mathrm{MoO}$ shows a small increase (about 20\%) in the current density with respect to the one without $\mathrm{MoO}_{3}$. This indicates that the influence of p-doping induced by the $\mathrm{MoO}_{3}$ diffusion on the $J-V$ curve is relatively small compared to the 5 -fold change due to the injection enhancement. Therefore, it is found that the change in the $J-V$ curves in Fig. 2a is mainly caused by the ITO modification effect of $\mathrm{MoO}_{3}$ that diffuses through the NPB layer and reaches the ITO/NPB interface. The optimum thickness of the NPB interlayer at which the device reaches the highest hole current can be used to measure the extent that how
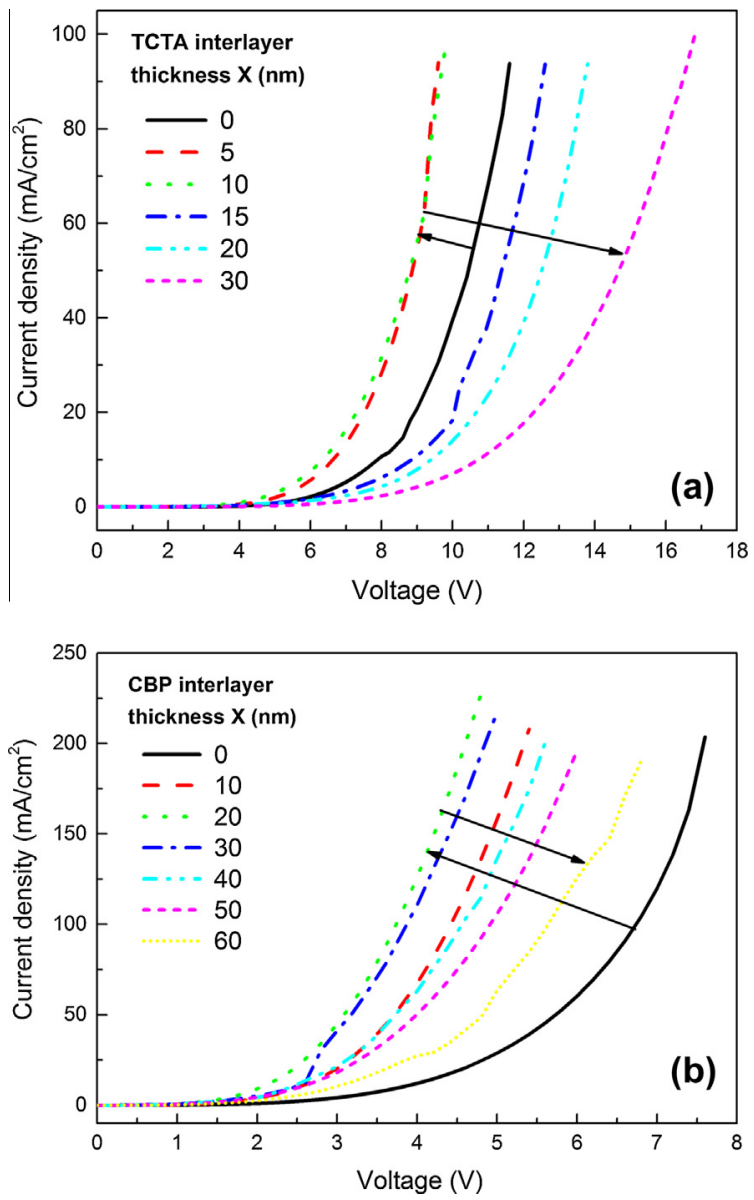

Fig. 3. (a) $J-V$ curves of the hole only device using a structure of ITO/ $\mathrm{TCTA}(x \mathrm{~nm}) / \mathrm{MoO}_{3}(3 \mathrm{~nm}) / \mathrm{TCTA}(165-x \mathrm{~nm}) / \mathrm{MoO}_{3}(3 \mathrm{~nm}) / \mathrm{Al}$, with $x$ varied from 0 to $30 \mathrm{~nm}$; (b) $J-V$ curves of the hole only device using a structure of $\mathrm{ITO} / \mathrm{CBP}(x \mathrm{~nm}) / \mathrm{MoO}_{3}(3 \mathrm{~nm}) / \mathrm{CBP}(165-x \mathrm{~nm}) / \mathrm{MoO}_{3}(3 \mathrm{~nm}) /$ $\mathrm{Al}$, with $x$ varied from 0 to $60 \mathrm{~nm}$.

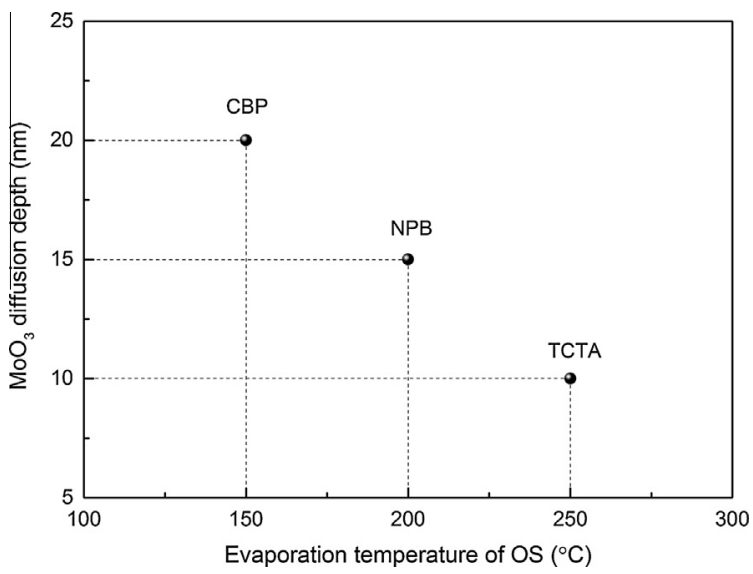

Fig. 4. Diffusion depths of $\mathrm{MoO}_{3}$ into different OSs as a function of the evaporation temperature of the OS.

far the $\mathrm{MoO}_{3}$ can diffuse. From Fig. 2a, the optimum thickness of the NPB interlayer is determined to be about $15 \mathrm{~nm}$. 


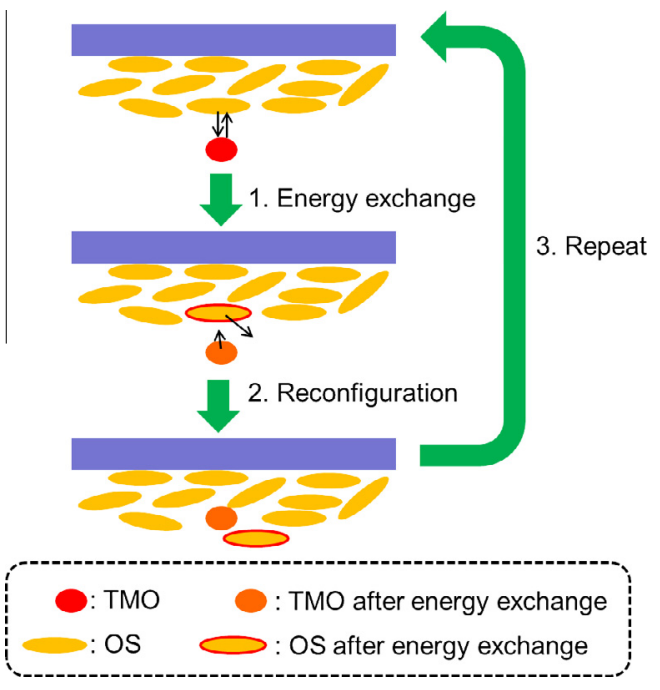

Fig. 5. Schematic view of the TMO diffusing into the OS film process.
3.3. $\mathrm{MoO}_{3}$ diffusion into other hole transporting materials and effect of the evaporation temperature of OSs on the diffusion

We further checked $\mathrm{MoO}_{3}$ on other two widely used hole transporting OSs, TCTA and CBP. As shown in Fig. 3a and $b$, the case for TCTA and CBP mimics that of NPB and the optimum thicknesses for the TCTA and CBP interlayers are about $10 \mathrm{~nm}$ and $20 \mathrm{~nm}$, respectively.

As shown in Fig. 4, we plot the diffusion depth (the optimum OS interlayer thickness determined by the $J-V$ study) of $\mathrm{MoO}_{3}$ into different OSs as a function of their evaporation temperatures (the temperature at which the OS can be evaporated at a rate of $0.1 \mathrm{~nm} / \mathrm{s}$ ). The evaporation temperature of the three OSs we use here are far lower than that of $\mathrm{MoO}_{3}$ (above $500{ }^{\circ} \mathrm{C}$ ). We can infer from Fig. 4 that the diffusion depth shows a monotonic increase as the evaporation temperature of the OS decreases. As we know, the evaporation temperature of the OS reflects its thermal stability, thus, the more thermally stable the OS is the harder the $\mathrm{MoO}_{3}$ can diffuse into the OS thin film. This process can be effectively visualized by Fig. 5. In Fig. 5, when the energetic TMO cluster reaches the OS film, it may knock through and ends up somewhere inside the TMO.
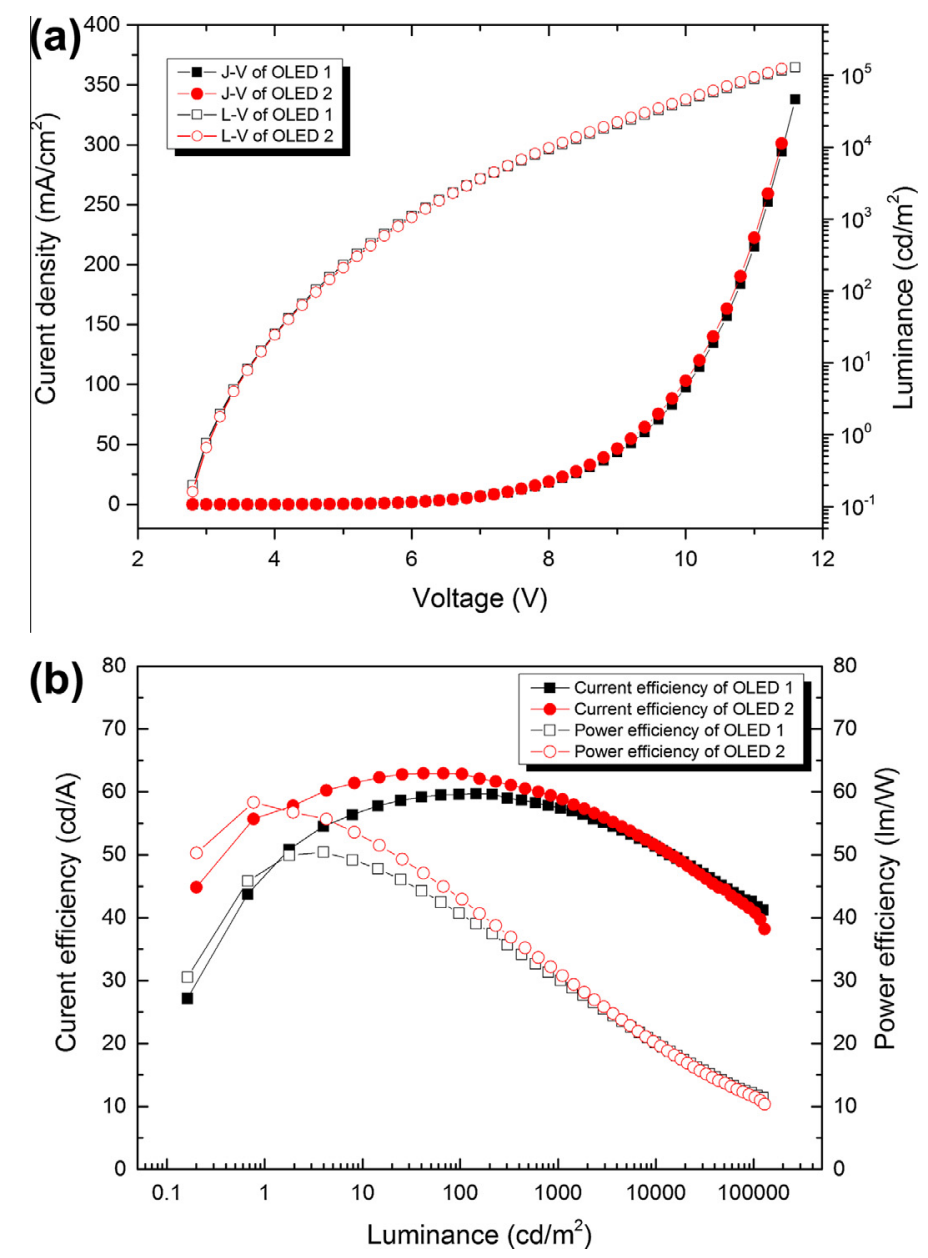

Fig. 6. (a) $J-V$ and $L-V$ curves of OLED 1 and 2, and (b) current efficiencies and power efficiencies of OLED 1 and 2. 
With a lower evaporation temperature OS, this process is more significant, i.e. more deeper into OS.

From the above studies, by considering the fact that the evaporation temperatures of most TMOs are much higher than common OSs, it is believed that the TMO diffusion into the OS process is a common phenomenon. For example, the OLEDs and OSCs employing an inverted structure always use TMO-on-OS structures as the hole injection/ transportation or hole extraction layer, however, few of the studies point out the mixing nature.

\subsection{Application of TMO-on-OS in organic optoelectronic devices}

Actually, the simultaneous anode modification and ptype doping employing TMO-on-OS structure would benefit the device application, which can simplify the fabrication processes by eliminating the doping process. To investigate this, we compared two OLEDs: OLED 1 with $\mathrm{MoO}_{3}$ doped CBP HTL and OLED 2 with $\mathrm{MoO}_{3}$ on CBP structure. The detailed device structures for OLED 1 and OLED 2 are ITO/CBP:9.1 vol.\% $\mathrm{MoO}_{3}(66 \mathrm{~nm}) / \mathrm{CBP}(20 \mathrm{~nm}) /$ CBP:8 wt.\% fac-tris(2-phenylpyridine)Iridium $\left[\operatorname{Ir}(\mathrm{ppy})_{3}\right]$ (20 nm)/1,3,5-Tri(1-phenyl-1H-benzo[d]imidazol-2-yl)phenyl $[\mathrm{TPBi}](50 \mathrm{~nm}) / \mathrm{LiF}(1 \mathrm{~nm}) / \mathrm{Al}$ and $\operatorname{ITO} / \mathrm{CBP}(30 \mathrm{~nm}) /$ $\mathrm{MoO}_{3}(3 \mathrm{~nm}) / \mathrm{CBP}(30 \mathrm{~nm}) / \mathrm{MoO}_{3}(3 \mathrm{~nm}) / \mathrm{CBP}(20 \mathrm{~nm}) / \mathrm{CBP}: 8$ wt.\%Ir(ppy) $)_{3}(20 \mathrm{~nm}) / \mathrm{TPBI}(50 \mathrm{~nm}) / \mathrm{LiF}(1 \mathrm{~nm}) / \mathrm{Al}$, respectively. The amount of $\mathrm{MoO}_{3}$ used in the two OLEDs is kept the same. The $J-V$ and $L-V$ curves of the two OLEDs are shown in Fig. 6a. As can be seen, the difference between the $J-V$ and $L-V$ curves of the two OLEDs is quite small, indicating that the $\mathrm{MoO}_{3}$ on CBP based HTL is quite efficient for hole injection and transportation. The current efficiencies (CEs) and power efficiencies (PEs) of the two OLEDs are shown in Fig. 6 b. As expected from the $J-V$ and $L-V$ curves, the efficiency of two devices should be close. OLED 1 shows a maximum CE of $59 \mathrm{~cd} / \mathrm{A}$, while it is $62 \mathrm{~cd} / \mathrm{A}$ for OLED 2. These efficiencies are comparable with the literature report [33]. We further studied the lifetime performance of
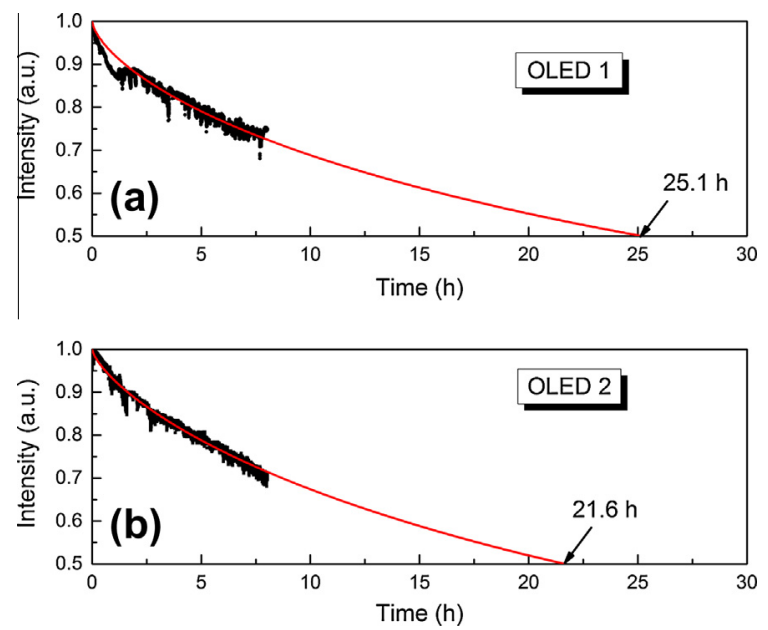

Fig. 7. (a) Lifetime data for OLED 1 at a constant driving current density of $11 \mathrm{~mA} / \mathrm{cm}^{2}$, with an initial luminance level of $5600 \mathrm{~cd} / \mathrm{m}^{2}$, and (b) lifetime data for OLED 2 at a constant driving current density of $11 \mathrm{~mA} / \mathrm{cm}^{2}$, with an initial luminance level of $5800 \mathrm{~cd} / \mathrm{m}^{2}$. the two OLEDs. As shown in Fig. 7, at a constant driving current density of $11 \mathrm{~mA} / \mathrm{cm}^{2}$, the fitted lifetimes for OLED 1 and 2 are about $25.1 \mathrm{~h}$ and $21.6 \mathrm{~h}$ (with initial luminance levels of 5600 and $5800 \mathrm{~cd} / \mathrm{m}^{2}$, respectively). As we can see, the lifetime difference between the two OLEDs is very small. It is expected that after further optimization on the layer thicknesses of $\mathrm{MoO}_{3}$ and $\mathrm{CBP}$, an even better lifetime can possibly be achieved in OLED 2 .

\section{Conclusion}

In conclusion, deposition of TMO on OS results in the mixing of TMO and OS due to the diffusion of TMO into OS, which has been wrongly understood before. We show that this is a thermal driven process and the diffusion depth tends to be larger in OS with a lower evaporation temperature. As the evaporation temperatures of most TMOs are much higher than those of common OSs, we believe this diffusion process is very common. We also show that this process is good for the simplification of the device fabrication and TMO-on-OS structure can replace TMO doped OS structure commonly used in modern organic optoelectronic devices.

\section{Acknowledgements}

This work is supported by the National Research Foundation of Singapore under Grant Nos. NRF-CRP-6-2010-2 and NRF-CRP-11-2012-01, and the Singapore Agency for Science, Technology and Research (A*STAR) SERC under Grant Nos. 1121202009 and 092101 0057. This work is also supported by National Natural Science Foundation of China (NSFC) (Project Nos. 61006037 and 61076015).

\section{References}

[1] J. Meyer, S. Hamwi, M. Kröger, W. Kowalsky, T. Riedl, A. Kahn, Adv. Mater. 24 (2012) 5408.

[2] M.T. Greiner, M.G. Helander, W.-M. Tang, Z.-B. Wang, J. Qiu, Z.-H. Lu, Nat. Mater. 11 (2012) 76

[3] H. You, Y. Dai, Z. Zhang, D. Ma, J. Appl. Phys. 101 (2007) 026105.

[4] J. Meyer, S. Hamwi, T. Bulow, H.H. Johannes, T. Riedl, W. Kowalsky, Appl. Phys. Lett. 91 (2007) 113506.

[5] J. Meyer, K. Zilberberg, T. Riedl, A. Kahn, J. Appl. Phys. 110 (2011) 033710.

[6] D.-S. Leem, H.-D. Park, J.-W. Kang, J.-H. Lee, J.W. Kim, J.-J. Kim, Appl. Phys. Lett. 91 (2007) 011113.

[7] C.W. Tang, S.A. Vanslyke, Appl. Phys. Lett. 51 (1987) 913.

[8] C.C. Chang, J.F. Chen, S.W. Hwang, C.H. Chen, Appl. Phys. Lett. 87 (2005) 253501.

[9] H. Kanno, R.J. Holmes, Y. Sun, S. Kena-Cohen, S.R. Forrest, Adv. Mater. 18 (2006) 339.

[10] L.S. Liao, K.P. Klubek, C.W. Tang, Appl. Phys. Lett. 84 (2004) 167.

[11] C.W. Tang, Appl. Phys. Lett. 48 (1986) 183.

[12] A.K.K. Kyaw, X.W. Sun, C.Y. Jiang, G.Q. Lo, D.W. Zhao, D.L. Kwong, Appl. Phys. Lett. 93 (2008) 221107.

[13] G. Li, C.W. Chu, V. Shrotriya, J. Huang, Y. Yang, Appl. Phys. Lett. 88 (2006) 253503.

[14] V. Shrotriya, G. Li, Y. Yao, C.W. Chu, Y. Yang, Appl. Phys. Lett. 88 (2006) 073508

[15] A.G.F. Janssen, T. Riedl, S. Hamwi, H.H. Johannes, W. Kowalsky, Appl. Phys. Lett. 91 (2007) 073519.

[16] D.W. Zhao, X.W. Sun, C.Y. Jiang, A.K.K. Kyaw, G.Q. Lo, D.L. Kwong, Appl. Phys. Lett. 93 (2008) 083305.

[17] M. Kroger, S. Hamwi, J. Meyer, T. Riedl, W. Kowalsky, A. Kahn, Appl. Phys. Lett. 95 (2009) 123301.

[18] J. Meyer, M. Kroger, S. Hamwi, F. Gnam, T. Riedl, W. Kowalsky, A. Kahn, Appl. Phys. Lett. 96 (2010) 193302. 
[19] Y. Yi, P.E. Jeon, H. Lee, K. Han, H.S. Kim, K. Jeong, S.W. Cho, J. Chem. Phys. 130 (2009) 094704.

[20] J.-H. Li, J. Huang, Y. Yang, Appl. Phys. Lett. 90 (2007) 173505.

[21] Y.B. Zhao, J.S. Chen, W. Chen, D.G. Ma, J. Appl. Phys. 111 (2012) 043716.

[22] X. Mu, X.-M. Wu, Y.-L. Hua, Z.-Q. Jiao, L.-Y. Shen, Y.-J. Su, J.-J. Bai, W.T. Bi, S.-G. Yin, J.-J. Zheng, Chin. Phys. B 22 (2013) 027805.

[23] Z. Chen, I. Santoso, R. Wang, L.F. Xie, H.Y. Mao, H. Huang, Y.Z. Wang, X.Y. Gao, Z.K. Chen, D. Ma, A.T.S. Wee, W. Chen, Appl. Phys. Lett. 96 (2010) 3.

[24] M. Kroger, S. Hamwi, J. Meyer, T. Riedl, W. Kowalsky, A. Kahn, Org. Electron. 10 (2009) 932.

[25] J. Meyer, T. Winkler, S. Hamwi, S. Schmale, H.-H. Johannes, T. Weimann, P. Hinze, W. Kowalsky, T. Riedl, Adv. Mater. 20 (2008) 3839.

[26] J. Kwak, W.K. Bae, D. Lee, I. Park, J. Lim, M. Park, H. Cho, H. Woo, D.Y. Yoon, K. Char, S. Lee, C. Lee, Nano Lett. 12 (2012) 2362.
[27] L.-M. Chen, Z. Hong, G. Li, Y. Yang, Adv. Mater. 21 (2009) 1434.

[28] Y. Zou, Z. Deng, Z. Lv, Z. Chen, Y. Yin, H. Du, Y. Wang, in: Proc. SPIE 7658 , 5th International Symposium on Advanced Optical Manufacturing and Testing Technologies: Optoelectronic Materials and Devices for Detector, Imager, Display, and Energy Conversion Technology, 76580S, October 21, 2010.

[29] Y. Zou, Z. Deng, Z. Lv, Z. Chen, D. Xu, Y. Chen, Y. Yin, H. Du, Y. Wang, J. Lumin. 130 (2010) 959.

[30] G. Parthasarathy, C. Shen, A. Kahn, S.R. Forrest, J. Appl. Phys. 89 (2001) 4986.

[31] C.-C. Chang, M.-T. Hsieh, J.-F. Chen, S.-W. Hwang, C.H. Chen, Appl. Phys. Lett. 89 (2006) 253504.

[32] T. Matsushima, H. Murata, Appl. Phys. Lett. 95 (2009) 203306.

[33] Z.W. Liu, M.G. Helander, Z.B. Wang, Z.H. Lu, Appl. Phys. Lett. 94 (2009) 113305. 